CASE REPORT

\title{
Combined Large Cell Neuroendocrine Carcinoma with Both Adenocarcinoma and Squamous Cell Carcinoma
}

\author{
Yuki Tenjin'1; Hideshi Uramoto1; Hironori Kobayashi'; \\ Mitsuhiro Matsumoto1; Takaaki Ito2; Hirotsugu Kohrogi3
}

\begin{abstract}
Background. Combined large cell neuroendocrine carcinoma (LCNEC) is a rare histological type of primary lung cancer. Case. We experienced the case of a 60 -year-old man who had a solid round lung nodule measuring $16 \times 11 \mathrm{~mm}$ located in the right $\mathrm{S}^{6}$. The patient underwent radical surgery, and histopathology revealed LCNEC combined with adenocarcinoma (Ad) and squamous cell carcinoma (Sq), defined as pathological T1aN1M0 stage IIA disease. He received adjuvant chemotherapy with cisplatin $\left(60 \mathrm{mg} / \mathrm{m}^{2}\right.$, day 1$)$ and
\end{abstract}

irinotecan $\left(60 \mathrm{mg} / \mathrm{m}^{2}\right.$, day $\left.1,8,15\right)$ for a total of four cycles and has since been followed without evidence of recurrence for one year after the surgery. Conclusions. We herein present an extremely rare case of cancer consisting of combined LCNEC with both Ad and Sq.

(JJLC. 2015;55:89-92)

KEY WORDS — Lung cancer, Combined large cell neuroendocrine carcinoma, Adenocarcinoma, Squamous cell carcinoma

\section{INTRODUCTION}

Large cell neuroendocrine carcinoma (LCNEC) is a highgrade neuroendocrine tumor of the lung, and its heterogeneous group was classified by Travis et al. in $1991 .^{1}$ In 1999, the World Health Organization (WHO) categorized combined LCNEC as a variant of large cell carcinoma (LCC). ${ }^{2}$ Combined LCNEC is a rare histological type of primary lung carcinoma that contains components of LCNEC with adenocarcinoma (Ad), squamous cell carcinoma (Sq), giant cell carcinoma and/or spindle cell carcinoma. ${ }^{3}$ Combined LCNEC accounts for approximately only $10.6 \%$ of all LCNECs. ${ }^{4}$ We herein report an extremely rare case of combined LCNEC that contained both Ad and Sq of the lung.

\section{CASE REPORT}

A 60-year-old Japanese man was admitted to Kumamoto Saishunso National Hospital for the treatment of a solid round nodule in the right $\mathrm{S}^{6}$ measuring $16 \times 11 \mathrm{~mm}$ in di- ameter on thoracic computed tomography (CT) (Figure 1A). He was a current smoker with a smoking history of $1 \mathrm{pack} /$ day for 40 years. There were no physical signs or symptoms, and laboratory tests showed only elevation of the serum carcinoembryonic antigen (CEA) level at $11.27 \mathrm{ng} / \mathrm{ml}$. A CT-guided needle biopsy showed a diagnosis of primary lung cancer, although the histological type was not determined. ${ }^{18} \mathrm{~F}$-fluorodeoxyglucose positron emission tomography ( ${ }^{18}$ FDG-PET) images revealed radiotracer accumulation in the pulmonary nodule (maximum standardized uptake value, 7.9) and right hilar lymph nodes (\# 11, \# 12) (Figure 1B, 1C). Contrast magnetic resonance imaging (MRI) demonstrated no brain metastasis. Therefore, we diagnosed the patient with primary lung cancer, clinical $\mathrm{T} 1 \mathrm{aN} 1 \mathrm{M} 0$ stage IIA. Right lower lobectomy and mediastinal lymph node dissection (ND2a-2) were performed, and the maximum horizontal cut surface of the tumor was treated with hematoxylin-eosin staining (Figure $2 \mathrm{~A}$ ). The surgical specimen showed a yellowish-white solid tumor (Figure

Respiratory Medicine, Kumamoto University Hospital, Faculty of Life Sciences, Kumamoto University, Japan.

Received December 23, 2014; accepted March 7, 2015.
1Department of Respiratory Medicine, Kumamoto Saishunso National Hospital, National Hospital Organization, Japan; ${ }^{2}$ Department of Pathology and Experimental Medicine, Graduate School of Medical Sciences, Kumamoto University, Japan; ${ }^{3}$ Department of 

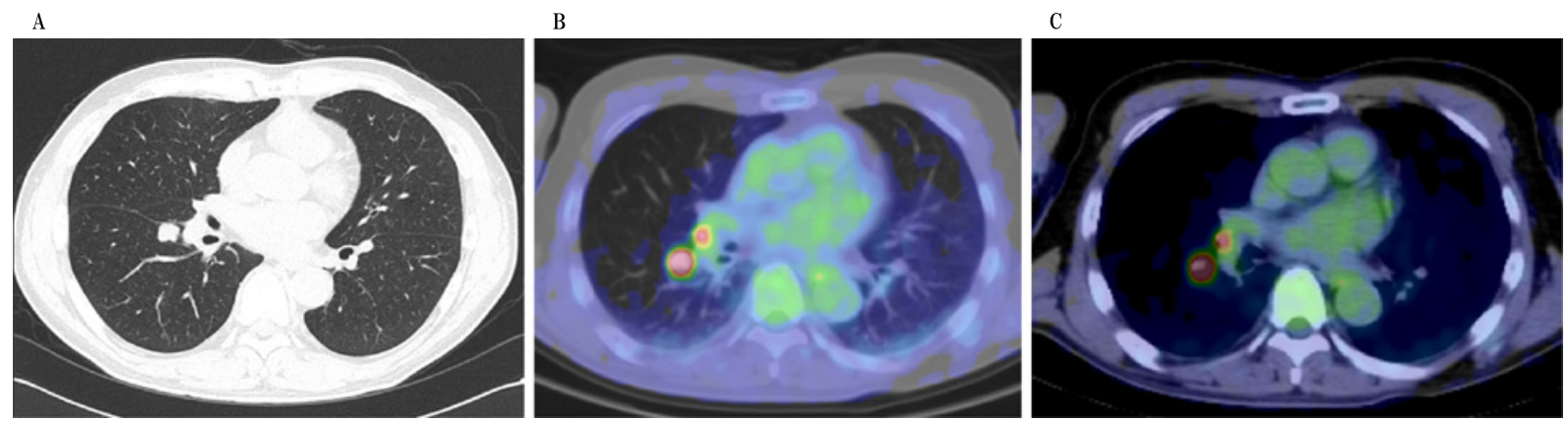

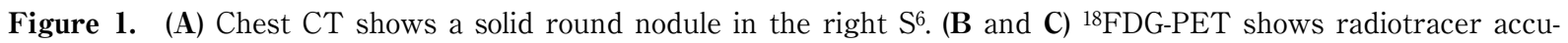
mulation in the pulmonary nodule and right hilar lymph nodes (C: \#11, B: \#12).
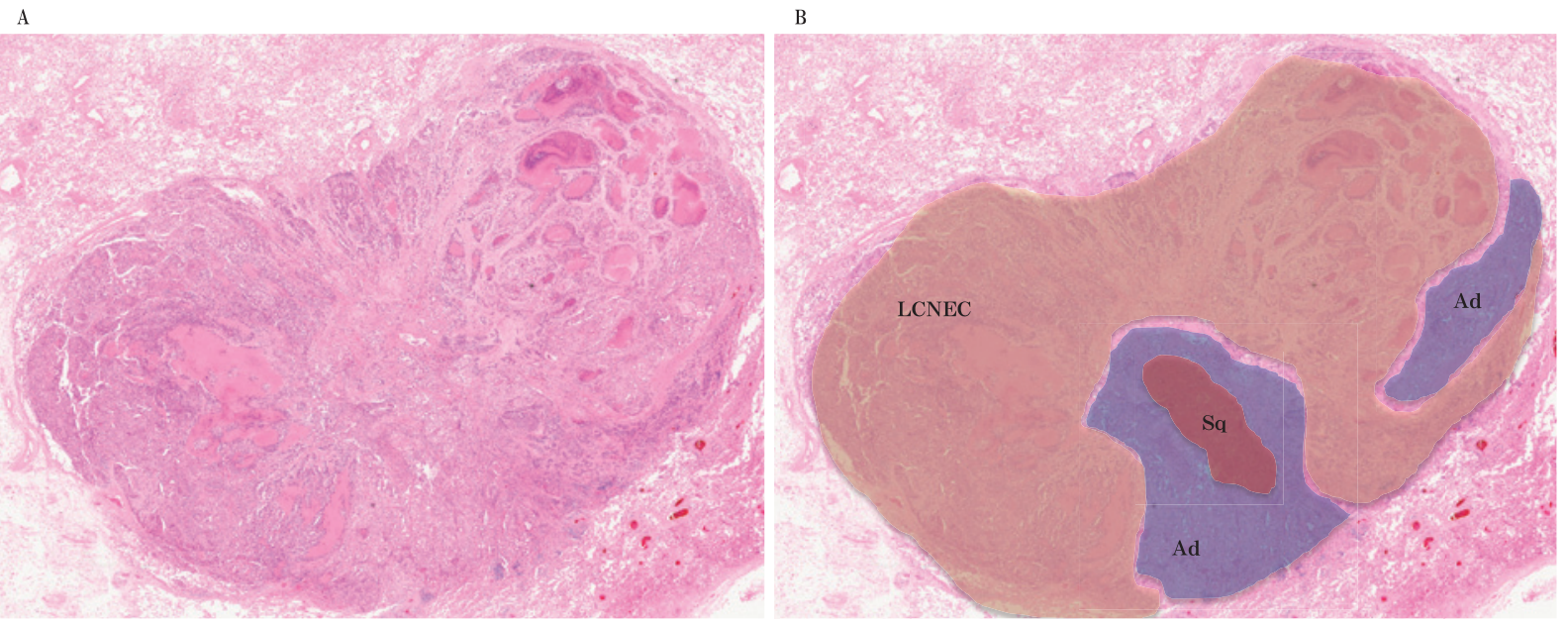

Figure 2. (A) Maximum horizontal cut surface of the tumor stained with hematoxylin and eosin. (B) The large cell neuroendocrine carcinomatous component is shown in yellow, the adenocarcinomatous component is shown in blue and the squamous cell carcinomatous component is shown in red. There are no apparent overlapping carcinomatous findings.

3A), and the histopathological examination disclosed carcinoma with a trabecular growth pattern containing central necrosis (Figure 3B). The tumor cells were large, exhibiting abundant cytoplasm with prominent nucleoli (Figure 3C), which suggested LCNEC. The tumor also contained a component with a glandular structure (Figure 3D) and atypical cells displaying keratinization (Figure $3 \mathrm{E}$ ) in other parts, indicating $\mathrm{Ad}$ and $\mathrm{Sq}$, respectively. The tumor cells comprised three histological elements with no apparent overlapping carcinomatous findings. The adenocarcinomatous component occupied approximately $15-20 \%$ of the tumor, while the squamous cell carcinomatous component occupied 5\% (Figure 2B). An immunohistochemical examination revealed positive staining for neural cell adhesion molecule (NCAM) (Fig- ure 3F), chromogranin-A (CGA) (Figure 3G) and synaptophysin (Figure $3 \mathrm{H}$ ), indicative of neuroendocrine differentiation of the tumor. Napsin A and p40 were also positive in each component of Ad and Sq (Figure 3I, 3J). Based on the findings of the histopathological and immunohistochemical examinations, the tumor was diagnosed as the combined histological type of LCNEC with Ad and Sq. The patient subsequently received adjuvant chemotherapy with cisplatin $\left(60 \mathrm{mg} / \mathrm{m}^{2}\right.$, day 1$)$ and irinotecan $\left(60 \mathrm{mg} / \mathrm{m}^{2}\right.$, day $\left.1,8,15\right)$ for a total of four cycles and has since been followed without evidence of recurrence for one year after the surgery.

\section{DISCUSSION}

There are four subtypes of pulmonary neuroendocrine 

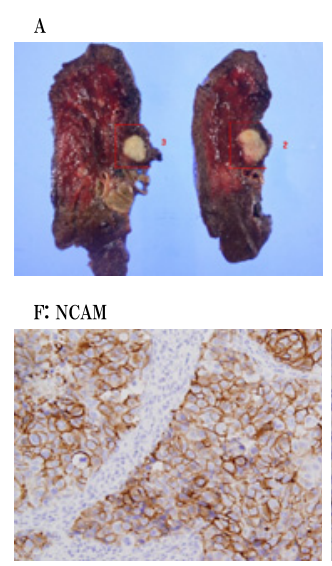
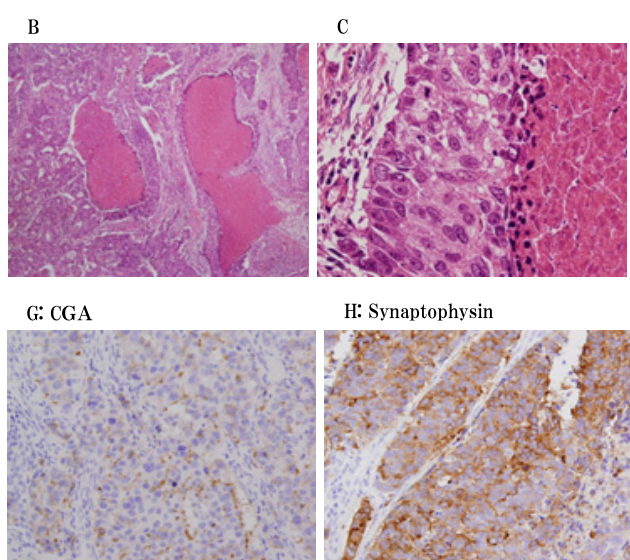

H: Synaptophysin

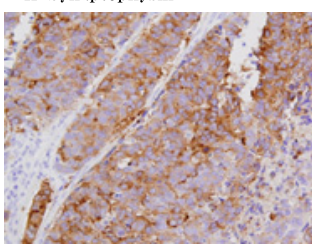

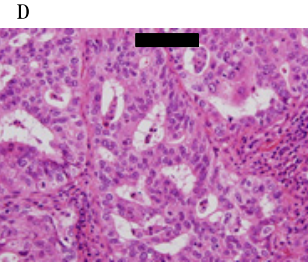

I: Napsin A

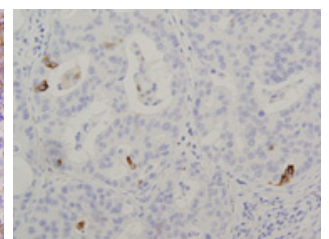

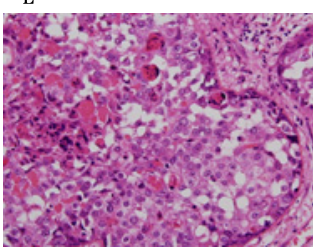

$\mathrm{J}: \mathrm{p} 40$

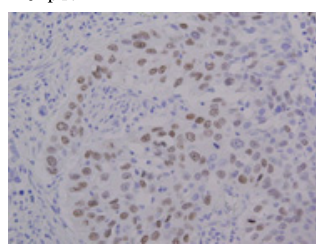

Figure 3. (A) A lung tumor is detected in the lung hilum, presenting as a yellowish-white solid mass measuring $16 \times 11 \mathrm{~mm}$. (B) Hematoxylin-eosin staining shows carcinoma tissue with a trabecular growth pattern containing central necrosis. (C) The tumor cells are large and have abundant cytoplasm with prominent nucleoli, which suggests LCNEC. (D) A glandular structure is seen, which indicates an adenocarcinomatous component. (E) Atypical cells with keratinization are noted in the other parts, indicative of a squamous cell carcinomatous component. ( $\mathbf{F}, \mathbf{G}$ and $\mathbf{H})$ The immunohistochemical examination shows positive staining for neural cell adhesion molecule (NCAM), chromograninA (CGA) and synaptophysin, which suggests neuroendocrine differentiation of the tumor. (I) Napsin A is positive in the component of adenocarcinoma. (J) p40 is positive in the component of squamous cell carcinoma.

tumors according to the clinicopathological, morphological and biological features: typical carcinoid (TC), atypical carcinoid (AC), small cell carcinoma and LCNEC. ${ }^{2}$ TC and $\mathrm{AC}$ are classified into low- to intermediate-grade malignant tumors, while small cell carcinoma and LCNEC are high-grade malignant tumors. The development of LCNEC is closely related to a positive smoking history, and its incidence is high in men, especially at old ages. It has been pointed out that the CEA levels are more likely to be elevated in LCNEC patients as a tumor marker. ${ }^{5}$ The histological criteria for LCNEC proposed by the WHO in 1999 are as follows: 1) a tumor with neuroendocrine morphological features (organoid nesting, palisading, rosettes and trabeculae); 2) a high mitotic rate of $\geq 11$ mitoses per $2 \mathrm{~mm}^{2} ; 3$ ) necrosis (often in large zones); 4) cytological features of non-small cell carcinoma (NSCLC), that is, a large cell size, low nuclear to cytoplasmic ratio, vesicular or fine chromatin and/or frequent nucleoli. LCNEC lesions are defined as being positive for one or more neuroendocrine markers, such as chromogranin, synaptophysin and NCAM, as assessed on immunohistochemical examinations. ${ }^{2}$ Combined LCNEC is categorized as LCNEC with components of Ad, Sq and/or spindle cell carcinoma. The combined type of LCNEC with small cell carcinoma is defined as combined small cell carcinoma, distinctively. ${ }^{3}$ There are no definitive histopathological criteria for combined
LCNEC to differentiate LCNEC in terms of the grade of combination of Ad, Sq, giant cell carcinoma and/or spindle cell carcinoma. Asamura et al. showed that the prevalence of LCNEC is approximately $3 \%$ in lung cancer patients and the prevalence of combined LCNEC is $10.6 \%$ of cases of LCNEC, in which the prevalence of combined LCNEC with Ad, Sq and others is 3.5\%, 5.7\% and $1.4 \%$, respectively. ${ }^{4}$ Kobayashi et al. reported combined LCNEC with Ad in two cases, Sq in two cases, both Sq and small cell carcinoma in two cases and spindle cell carcinoma in one case. ${ }^{6}$ Maeda et al. also reported surgically resected combined LCNEC with Ad in one case, Sq in one case and small cell carcinoma in two cases. ${ }^{7}$ Additionally, Hayashi et al. reported a case of combined LCNEC with giant cell carcinoma. ${ }^{8}$ These cases involved combined LCNEC with only one cancer consisting of Ad, Sq, small cell carcinoma, spindle cell carcinoma or giant cell carcinoma, with the exception of both Sq and small cell carcinoma in two cases. Because the present case included the mixed histopathological type of LCNEC with both Ad and Sq of the lung, it is extremely rare. As for the histogenesis of neuroendocrine tumors admixed with other histopathological components, this issue remains unclear. In other organs, Noske et al. reported a case of combined adenosquamous carcinoma and LCNEC of the gallbladder. ${ }^{9}$ They hypothesize that neuroendocrine cells may occur in non-neoplastic 
epithelium that exhibits hyperplastic or metaplastic changes. Because these cells might stem from a common pluripotent precursor, this finding may be related to the differentiation of these cells into various histopathological types of carcinoma, as in the present case. It is known that surgery alone is not adequate to achieve a cure for LCNEC, especially in cases of combined LCNEC. Ruffini et al. indicated that lung tumors with a mixed histopathological pattern present with a more aggressive clinicopathological behavior and reduced survival as compared to the single histopathology population of resected lung tumors. ${ }^{10}$ Therefore, adjuvant chemotherapy is often performed after surgery, even in patients with the early pathological stage of LCNEC. ${ }^{11}$ The efficacy of platinum containing anti-cancer drugs and etoposide (VP-16) or irinotecan (CPT-11) regimens have been evaluated. ${ }^{12-14}$ In the current case, we administered cisplatin and irinotecan after surgery. There has been no evidence of recurrence for one year after the surgery, and it is necessary to continue careful observation. Further studies of combined LCNEC are required to elucidate the biological properties of and identify more effective therapies for these lesions.

本論文内容に関連する著者の利益相反：なし

\section{REFERENCES}

1. Travis WD, Linnoila RI, Tsokos MG, Hitchcock CL, Cutler GB Jr, Nieman L, et al. Neuroendocrine tumors of the lung with proposed criteria for large-cell neuroendocrine carcinoma. An ultrastructural, immunohistochemical, and flow cytometric study of 35 cases. Am J Surg Pathol. 1991;15:529-553.

2. Travis WD, Colby TV, Corrin B, Shimosato Y, Brambilla E. WHO International Histological Classification of Tumours. Histological Typing of Lung and Pleural Tumours. 3 rd ed.
Berlin: Springer; 1999:8.

3. The Japan Lung Cancer Society. General Rule for Clinical and Pathological Record of Lung Cancer. 7th ed. 2010:80.

4. Asamura H, Kameya T, Matsuno Y, Noguchi M, Tada H, Ishikawa Y, et al. Neuroendocrine neoplasms of the lung: a prognostic spectrum. J Clin Oncol. 2006;24:70-76.

5. Iyoda A, Hiroshima K, Nakatani Y, Fujisawa T. Pulmonary large cell neuroendocrine carcinoma. JJLC. 2006;46: 315-320.

6. Kobayashi N, Kinoshita S, Dohi T. A case of combined large cell neuroendocrine carcinoma (LCNEC) and adenocarcinoma. Jpn J Chest Surg. 2005;19:656-660.

7. Maeda R, Isowa N, Kawasaki Y, Tokuyasu H, Touge H. Primary lung carcinoma with a component of large cell neuroendocrine carcinoma (LCNEC). JJLC. 2008;48:693699.

8. Hayashi S, Kitada M, Ishibashi K, Matsuda Y, Miyokawa $\mathrm{N}$. Combined large cell neuroendocrine carcinoma with giant cell carcinoma of the lungs: a case report. World $J$ Surg Oncol. 2013;11:205.

9. Noske A, Pahl S. Combined adenosquamous and largecell neuroendocrine carcinoma of the gallbladder. Virchows Arch. 2006;449:135-136.

10. Ruffini E, Rena O, Oliaro A, Filosso PL, Bongiovanni M, Arslanian A, et al. Lung tumors with mixed histologic pattern. Clinico-pathologic characteristics and prognostic significance. Eur J Cardiothorac Surg. 2002;22:701-707.

11. Nakamura T, Ueda K, Tanaka T, Hayashi M, Hamano K. Combined large cell neuroendocrine carcinoma: Report of two cases. Jpn J Chest Surg. 2012;26:577-583.

12. Yamazaki S, Sekine I, Matsuno Y, Takei H, Yamamoto N, Kunitoh H, et al. Clinical responses of large cell neuroendocrine carcinoma of the lung to cisplatin-based chemotherapy. Lung Cancer. 2005;49:217-223.

13. Iyoda A, Hiroshima K, Moriya Y, Takiguchi Y, Sekine Y, Shibuya K, et al. Prospective study of adjuvant chemotherapy for pulmonary large cell neuroendocrine carcinoma. Ann Thorac Surg. 2006;82:1802-1807.

14. Fujiwara Y, Sekine I, Tsuta K, Ohe Y, Kunitoh H, Yamamoto N, et al. Effect of platinum combined with irinotecan or paclitaxel against large cell neuroendocrine carcinoma of the lung. Jpn J Clin Oncol. 2007;37:482-486. 